University of Nebraska - Lincoln

DigitalCommons@University of Nebraska - Lincoln

6-2008

\title{
Social Network Characteristics and Risky Sexual and Drug Related Behaviors Among Homeless Young Adults
}

Kimberly A. Tyler

University of Nebraska-Lincoln, kim@ktresearch.net

Follow this and additional works at: https://digitalcommons.unl.edu/sociologyfacpub

Part of the Sociology Commons

Tyler, Kimberly A., "Social Network Characteristics and Risky Sexual and Drug Related Behaviors Among Homeless Young Adults" (2008). Sociology Department, Faculty Publications. 47.

https://digitalcommons.unl.edu/sociologyfacpub/47

This Article is brought to you for free and open access by the Sociology, Department of at DigitalCommons@University of Nebraska - Lincoln. It has been accepted for inclusion in Sociology Department, Faculty Publications by an authorized administrator of DigitalCommons@University of Nebraska - Lincoln. 
Published in Social Science Research, 37:2 (June 2008), pp. 673-685; doi 10.1016/j.ssresearch.2007.09.004

Published online October 24, 2007. Copyright (C) 2007 Elsevier Inc. Used by permission.

http://www.sciencedirect.com/science/journal/0049089X

\title{
Social network characteristics and risky sexual and drug related behaviors among homeless young adults
}

\author{
Kimberly A. Tyler \\ University of Nebraska-Lincoln, Department of Sociology, \\ 717 Oldfather Hall, Lincoln, NE 68588-0324, USA
}

\begin{abstract}
Although research finds high rates of risky sexual and drug related behavior among homeless young people, little research had examined how the characteristics of their social networks encourage or constrain risky behaviors. Based on a sample of 145 homeless young adults in the Midwestern United States, results revealed that having used alcohol with at least one of their network members and the presence of more conflict was associated with engaging in a greater number of sexual risk taking behaviors. Correlates of engaging in a greater number of substance use related behaviors included having older peers within the network, having used illicit drugs with at least one network member, and the presence of more conflict. The presence of a family member in one's network, however, was associated with fewer sexual and drug related risk behaviors. Overall, the social network characteristics of youth explained significant, additional variance beyond that of youth's own characteristics and their early family histories.
\end{abstract}

Keywords: social networks, homeless young adults, risky sexual behaviors, risky drug related behaviors

\section{Introduction}

Research finds that homeless young people engage in numerous risky sexual practices and drug related behaviors (Rotheram-Borus et al., 1992; Allen et al., 1994; Anderson et al., 1994; Kral et al., 1997; Kipke et al., 1998; Martinez et al., 1998; Ennett et al., 1999a; Ennett et al., 1999b; Tyler et al., 2000a; Tyler et al., 2000b). Despite considerable evidence that demographic and family risk factors are associated with risky outcomes, few studies have examined how the characteristics of homeless youth's current social networks encourage or constrain risky behaviors. Social networks are comprised of people with whom homeless young people associate and spend most of their time. If homeless young adults have networks that are comprised of members who coerce them to trade sex (Tyler and Johnson, 2006b) or who pressure them to use drugs (Tyler and Johnson, 2006a), then homeless young adults may be more likely to participate in these risky behaviors. In contrast, if homeless youth have social networks that provide protective functions (Hagan and McCarthy, 1997; Ennett et al., 1999a; Rice et al., 2007), then they may be less likely to engage in risky behaviors. 
The purpose of the current study is to (a) describe the social network characteristics of homeless young adults and (b) examine whether social network characteristics (e.g., network norms, conflict, stability, closeness) are associated with risky sexual and substance use related behaviors net of the effects of demographic and family history factors. Learning more about the risk and protective functions of social networks among homeless young adults is important for determining the scope and focus of intervention and prevention.

\section{Literature review}

\subsection{Risky sexual behavior}

Risky sexual practices are quite common among homeless youth. For example, rates of trading sex among homeless young people vary from 11\% to 46\% (Greenblatt and Robertson, 1993; Kipke et al., 1997; Kral et al., 1997; Martinez et al., 1998; Greene et al., 1999; Beech et al., 2002; Halcon and Lifson, 2004; Van Leeuwen et al., 2004). Other unsafe sexual practices include low rates of condom use: many studies find that less than one-half of homeless and runaway adolescents used a condom the last time they had sexual intercourse (Rotheram-Borus and Koopman, 1991; Anderson et al., 1994). Additionally, these young people report numerous sexual partners (Rotheram-Borus et al., 1992; Greenblatt and Robertson, 1993; Halcon and Lifson, 2004) and high rates of sexually transmitted diseases (Anderson et al., 1994; Forst, 1994; Goodman and Berecochea, 1994; Wagner et al., 2001; Halcon and Lifson, 2004).

\subsection{Substance use related behavior}

Research shows that homeless young people participate in numerous substance use related behaviors including illicit drug and alcohol use (Koopman et al., 1994; Greene et al., 1997; Bailey et al., 1998; Kipke et al., 1998; Chen et al., 2004; Van Leeuwen et al., 2004), injecting drugs and/or needle sharing (Greene et al., 1997; Kral et al., 1997; Bailey et al., 1998; Kipke et al., 1998), selling drugs (Hagan and McCarthy, 1997; Whitbeck and Hoyt, 1999), and receiving treatment for substance abuse problems (Smart and Ogborne, 1994; Whitbeck and Hoyt, 1999).

\subsection{Demographic correlates of risky behavior}

Sexual risk taking tends to vary by gender (Rotheram-Borus et al., 1992; Booth et al., 1999; MacKellar et al., 2000; Tyler et al., 2001; Montgomery et al., 2002), sexual orientation (Clatts and Davis, 1999), age (Clatts and Davis, 1999; Tyler et al., 2001; Whitbeck et al., 2001), and the frequency with which youth run from home (Janus et al., 1987; Ennett et al., 1999b; Tyler et al., 2000a).

Similarly, risky substance use related behaviors also vary by gender (Warheit and Biafora, 1991; Anderson et al., 1994; Greene et al., 1997; MacKellar et al., 2000), sexual orientation (Moon et al., 2000), age (Van Leeuwen et al., 2004), and the frequency with which youth run from home and/or spend time on the street (Ennett et al., 1999b; Whitbeck et al., 1999). The findings are mixed, however, in terms of which specific groups are higher or lower on the risk taking behaviors.

\subsection{Family history correlates of risky behavior}

Experiencing sexual abuse prior to leaving home is a risk factor for homeless youth's involvement in unsafe sexual practices (Johnson et al., 1996; Silbert and Pines, 1981; Rotheram-Borus et al., 1996; Tyler et al., 2000a; Tyler et al., 2001; Wenzel et al., 2006). For example, those who experienced sexual abuse were more likely to have engaged in trading sex for food, shelter, money and/or drugs (Tyler et al., 2000a) and reported a greater number of sexual partners (Tyler et al., 2001). Additionally, experiencing sexual victimization since leaving home is positively correlated with risky sexual behaviors (Ennett et al., 1999b; MacKellar et al., 2000; Tyler et al., 2000a; Tyler et al., 2001; Wenzel et al., 2006).

Many young homeless people are raised in family environments characterized by caregiver substance misuse (Fors and Rojek, 1991; Ginzler et al., 2003), and this has been found to be related to youth's own in- 
volvement in drug related behaviors (Fors and Rojek, 1991; Baron, 1999; Ginzler et al., 2003). For example, Kipke et al. (1996) found that one quarter of their sample of homeless young people were first introduced to substance usage by a family member. Research has also linked substance use among homeless and runaway youth to childhood abuse (McMorris et al., 2002; Chen et al., 2004) and some homeless young adults explicitly report using substances to cope with early child abuse (Tyler and Johnson, 2006a).

\subsubsection{Social network characteristics and risky behavior}

Social networks, which are comprised of people with whom homeless youth associate and spend most of their time, are important for understanding health and HIV risk related behaviors (Marsden, 2006). Young people may enter these groups by choice, by chance, by coercion, or for protection (Cairns et al., 1995; Hagan and McCarthy, 1997), and the behaviors, attitudes, and norms of the group may be either beneficial or detrimental to the homeless young person. For example, if network norms are consistent with drug and alcohol use and participation in these behaviors is valued within the group, the young person is likely afforded more opportunities to use alcohol and drugs and may model the behavior of other members (Bauman and Ennett, 1996). Additionally, individuals often conform to the attitudes and behaviors of their social networks, despite the risks inherent in the activities, in order to avoid possible sanctions for non-conformity imposed by members of the group (Fisher, 1988). Thus, homeless youth may be pressured or coerced by group members to engage in behavior (e.g., illicit drug use) that they otherwise would not (Tyler and Johnson, 2006a). Research also finds that homeless youth who use illicit drugs and engage in risky sexual practices generally have friends who engage in similar behaviors (Kipke et al., 1998). As such, the norms and behaviors of social networks may be detrimental to homeless young adults. Despite this, some research has found that social networks may also serve a protective role by discouraging risky practices, and are therefore a benefit to the homeless young adult (Hagan and McCarthy, 1997; Ennett et al., 1999a; Rice et al., 2007).

At present, however, there has been limited empirical study of the social network characteristics (e.g., conflict, stability, network norms) of homeless young adults and how these may positively or negatively influence their risky sexual and substance use related behaviors (for exceptions, see [Ennett et al., 1999a; Rice et al., 2005; Rice et al., 2007). Ennett and colleagues (1999a) found that homeless youth without a network were at greater risk for trading sex, having multiple sex partners, and using illicit drugs than those youth with a network. Additionally, those who named a sex partner in their network were also more likely to have an illicit drug user present and to have experienced pressure to use drugs and engage in prostitution. Having an illicit drug user present in the network was associated with having numerous sexual partners and participation in survival sex. Those with a sex partner present were also less likely to have worn a condom during their most recent sexual experience. Rice and colleagues (2005) found that having a greater density of drug using peers within a social network increased the likelihood that homeless youth themselves would use drugs (Rice et al., 2005). Finally Rice et al. (2007) found that having a greater number of peers in one's network that engaged in risky behaviors increased the likelihood that homeless youth would participate in HIV risk behaviors across time.

Ennett et al. (1999a) also noted some positive aspects of social networks. Youth who reported a greater level of closeness to their network members were less likely to have numerous sexual partners. Additionally, having a friend in the network (as opposed to a service provider, family member, etc.) buffered against survival sex. Positive functions of social networks noted by Hagan and McCarthy (1997) include members protecting homeless youth from out-group victimization and providing them with social support. Similarly, Ennew (1994) also notes the protective function that social networks provide and the sense of belonging that comes with group membership. Finally, Rice and colleagues (2007) found that having pro-social peers in one's network (e.g., peers who go to school regularly) decreased the likelihood that homeless youth would engage in HIV risk behaviors.

Networks that include at least one family member also provide a positive function. For example, Johnson et al. (2005) found that family members continue to provide both instrumental and emotional support to homeless youth and having family members in one's instrumental network was associated with lower frequency of alcohol use. Additionally, Milburn and colleagues (2005) found that strong family bonds predicted lower rates of behavioral problems across time and greater emotional support from family at baseline 
was associated with higher family bonds one year later indicating that family members continue to be an important influence for some youth. Although some research exists on the influence of social network characteristics on homeless young adult's risky behaviors, more research is needed to understand this process.

\section{Hypotheses}

Based on what is known about homeless youth's participation in risky behaviors and from the research that exists on their network members, the following hypotheses are put forth. First, it was hypothesized that having used alcohol or illicit drugs with a network member would be associated with engagement in a greater number of sexual and drug risk behaviors. Next, it was hypothesized that having experienced pressure from a network member to have sex or use drugs would be associated with participation in a greater number of risky behaviors. Third, it was hypothesized that having a family member in the network would buffer against risk taking behaviors. Fourth, it was expected that having a sex partner present in the network would be positively associated with sexual and drug related behaviors. Additionally, an older mean age of network members was expected to be positively correlated with risky behaviors. Next, positive functions of networks including stability, frequency of interaction, closeness, support, and lower conflict were expected to be negatively associated with risky outcomes. Finally, it was hypothesized that even after controlling for demographic and family factors, social network characteristics would add increased variance in explaining sexual and drug related behaviors.

\section{Method}

Data are from the Homeless Young Adult Project (HYAP), a pilot study designed to examine the effect of neglect and abuse histories on homeless young adult's mental health and high-risk behaviors. Over a period of approximately one year (from April of 2004 through June of 2005) 199 young adults were interviewed in three Midwestern cities including Des Moines, IA, and Omaha and Lincoln, NE. Of this total, 144 were homeless and 55 were housed at the time of the interview. Participants comprising the housed sample were obtained via peer nominations from the homeless youth. Despite being housed at the time of the interview, 28 out of the 55 housed young adults had extensive histories of being homeless and had run away from home numerous times. In fact, the 28 housed young adults with run away histories reported running away more times than the homeless youth (Mean $=5.72$ vs. 4.99) but this difference was not statistically significant. What differentiated these two groups was their housing status at the time of the interview, indicating that homelessness is a situation that is very fluid and not easily defined (Wright, 1991). The final sample included 145 young adults who were homeless or who had a history of running away and who had valid data on the variables of interest.

Experienced interviewers who have worked on past projects dealing with at-risk youth, who have served for several years in agencies and shelters that support homeless young people, and who are very familiar with local street cultures such as knowing where to locate youth and where they congregate, conducted interviews. Additionally, all interviewers had completed the Collaborative Institutional Review Board (IRB) Training Initiative course for the protection of human subjects in research.

Interviewers approached shelter residents and located eligible respondents in areas where street youth congregate. The sampling protocol included varying the times of the day on both weekdays and weekends that interviewers went to these locations. This protocol was conducted repeatedly over the course of 14 months. Approximately $25 \%$ of the sample was recruited from the street. Study eligibility required young people to be between the ages of 19 and 25 and homeless. Interviewers obtained informed consent from young adults prior to participation and told youth about the confidentiality of the study and that their participation was voluntary. The interviews, which were conducted in shelter interview rooms or quiet corners of fast food restaurants or coffee shops, lasted approximately one hour and all participants received \$25 for their involvement. Referrals for shelter, counseling services, and food services, were offered to the young adults at the time of the interview. Although field reporters did not formally tally screening rates, they reported that very few young adults refused to participate. The Institutional Review Board at the University of Nebraska-Lincoln approved this study. 


\section{Measures}

\subsection{Dependent variables}

Sexual risk taking behavior was measured using an index created from four dichotomous items (scored as $0=$ no and $1=$ yes) measuring whether or not the youth had: (1) ever traded sex, (2) engaged in voluntary vaginal or anal intercourse with more than 5 different partners in their lifetime, (3) neglected to use a condom the last time they engaged in sexual intercourse, and (4) ever had a sexually transmitted disease. A count variable was created (range $=0-4 ; \bar{X}=1.54$ ). This index takes into account multiple indicators of risky sexual behavior (adapted from Ennett et al., 1999a, 1999b).

Substance use related behavior was measured with an index created from six dichotomous items (scored as $0=$ no and $1=$ yes) measuring whether or not the youth had: (1) sold drugs since running away (or ever sold drugs for housed youth), (2) ever stayed in a hospital or other facility for substance abuse, (3) ever injected drugs, (4) ever shared needles when injecting drugs, (5) used a hard drug (crank, amphetamines, cocaine, opiates, hallucinogens, barbiturates, inhalants, or designer drugs) in the past year, and (6) engaged in binge drinking (five or more drinks at one time) in the past month. A count variable was created (range $=0$ $6 ; X=1.76$ ). This index takes into account multiple indicators of risky substance use related behavior (some items adapted from Ennett et al., 1999a, 1999b).

\subsection{Independent variables}

Social network characteristics. The social network measures were adopted from Ennett et al. (1999a). Youth were asked to provide the initials of up to two people that they see frequently or with whom they spend the majority of their time. This number was chosen because research has found the average number of network members of homeless youth to be approximately 2.5. Youth who named no one (7 youth) were coded as not having a network, were not asked any further questions, and were eliminated from further analyses. The remaining youth were asked a series of questions regarding their networks including demographics, role relationships, network norms, network sanctions, affective and interactional characteristics, and social support.

Demographics. Respondents were asked the age of each network member. If they were unsure they were asked to give "their best guess." Respondents listing only one network member were scored according to the single age response while those with two network members received the average score.

Role relationships categorized their network member's relationship to them (e.g., friend, family member, boyfriend/girlfriend). Because some research shows that having a family member in the network may buffer against high-risk behaviors (Ennett et al., 1999a), this variable was coded as 0 (no family members present) and 1 (at least 1 family member present). In addition, youth were asked if they had ever had sex with each network member. This measure was dichotomized as 0 (did not have sex with either member) and 1 (had sex with at least one network member).

Network norms (changed slightly from Ennett's version) were based on the youth reports of behaviors engaged in with network members, which included ever getting drunk or using drugs with each network member. Dichotomous variables were created indicating the presence or absence of each behavior within their network.

Network sanctions. Respondents were asked if they had ever been pressured to use drugs or have sex by any of their network members. Dichotomous variables were created to indicate the presence or absence of each type of pressure in their network.

Affective and interactional characteristics. Mean network stability ranged from 1 (known for a few hours) to 5 (known for a year or more). Mean network interaction, based on how often they saw each network member in the previous month ranged from 1 (saw them once or twice) to 4 (saw them every day). Mean network closeness ranged from 1 (not close at all) to 4 (very close), and mean network conflict was based on how often they had arguments or fights with each network member, ranging from 1 (never) to 4 (always).

Social support measured which network member youth could go to if they needed help with four types of social support: instrumental aid; advice about personal or private matters; protective support; and emotional 
support. These variables were each coded as 0 (no one listed), 1 (one network member listed), and 2 (two network members listed). These four items were summed and a single variable was created (range $=0-8$ ).

\subsection{Control variables}

A series of control variables were included in all multivariate analyses including gender $(0=$ male; $1=\mathrm{fe}-$ male), age (range $=19-26)$, sexual orientation $(0=$ gay $/$ lesbian $/$ bisexual; $1=$ heterosexual $)$, education $(0=7$ th grade or less to $7=$ some college $)$, employment $(0=$ worked less than 40 hours per week; $1=$ worked 40 hours or more per week), and number of times the youth had ever run away ( $1=$ once, to $6=21-51$ times).

Two separate models were estimated and appropriate correlates were included in each based on prior research. In the sexual risk taking model, measures of childhood sexual abuse and previous sexual victimization were included as controls. Sexual abuse was measured using seven items that focused on sexual abuse that the young person might have experienced while living at home (adapted from Whitbeck and Simons, 1990). For example, "Before you were on your own (when you were under 18), how often did any adult or someone at least 5 years older than you ask you to do something sexual or touch you sexually, like on your butt, thigh, breast or genitals ('private parts')?" Responses ranged from 0 (never) to 7 (more than once a day). Each of the seven items were dichotomized and a count variable was created (range 0-7). Sexual victimization was measured by asking youth questions such as: "How often have you been asked to touch someone sexually when you didn't want to and how often have you been sexually assaulted and/ or raped" since leaving home? Responses ranged from 0 (never) to 3 (many times). Each item was dichotomized and then a count variable was created (range 0-4) (adapted from Whitbeck and Simons, 1990).

In the substance use model, measures of physical abuse and caretaker drug abuse were included as controls. Physical abuse was measured using items from the Conflict Tactics Scale - Parent Child (CTS-PC) (Straus et al., 1998). Youth were asked, for example, how often they were hit with an object, hit with a fist or kicked hard, choked, or threatened or assaulted with a knife or a gun. Response categories ranged from 0 (never) to 6 (more than 20 times). The 12 items were dichotomized and a count variable was created (range 0-12). Finally, caretaker drug abuse (adapted from Hodgins et al., 1993) was measured by asking youth if they had ever thought that their caretaker had a drug problem, if they had ever encouraged their caretaker to quit using drugs, and if they ever fought or argued with their caretaker when he/she was high. A dichotomous variable was created with 1 indicating the presence of at least one drug abuse symptom and 0 signifying the absence of all drug abuse symptoms.

\subsection{Analytic strategy}

To address the first purpose of this study, univariate statistics were calculated to describe the personal social networks of youth. Youth characteristics and family history variables were also included. For the multivariate analyses, ordinary least squares (OLS) regression was used to examine correlates of sexual risk taking and substance use related behaviors. Finally, the F-change was examined to see if social network characteristics significantly improved the fit of the model beyond that explained by the young adult's own characteristics and their early family histories.

\section{Results}

\subsection{Demographic characteristics}

Table 1 shows that approximately $38 \%$ of the sample was female, $82 \%$ heterosexual, and $43 \%$ were employed full time. On average, the sample was 21.57 years old, had completed the 11th grade, and had run away from home approximately 2 to 5 times. On average, the youth in the sample reported experiencing approximately three different types of physical abuse $(\bar{X}=2.91 ; \mathrm{SD}=2.66)$ and 2 different types of sexual abuse $(\bar{X}=1.63$; SD $=2.17)$ before they were 18 years old, and approximately 1 type of sexual victimization thereafter $(\bar{X}=.81 ; \mathrm{SD}=1.30)$. Twenty-four percent of young adults had a caretaker who had a drug abuse problem. 
Table 1. Univariate statistics $(n=145)$

\begin{tabular}{|c|c|c|}
\hline & $N$ & Percent \\
\hline \multicolumn{3}{|l|}{ Dichotomous characteristics } \\
\hline Female & 55 & 37.9 \\
\hline Heterosexual & 119 & 82.1 \\
\hline Employed full time & 62 & 42.8 \\
\hline Caretaker drug problem & 35 & 24.1 \\
\hline Family member in network & 17 & 11.7 \\
\hline Has had sex with a network member & 58 & 40.0 \\
\hline Has used alcohol with a network member & 102 & 70.3 \\
\hline Has used drugs with a network member & 90 & 62.1 \\
\hline Pressured to use drugs by network member & 20 & 13.8 \\
\hline Pressured to have sex by network member & 13 & 9.0 \\
\hline Categorical/Continuous characteristics & Mean & SD \\
\hline Age in years & 21.57 & 2.12 \\
\hline Education level $^{\mathrm{a}}$ & .75 & 1.73 \\
\hline Number of times run away ${ }^{b}$ & 2.26 & 1.57 \\
\hline Sexual abuse & 1.63 & 2.17 \\
\hline Sexual victimization & .81 & 1.30 \\
\hline Physical abuse & 2.91 & 2.66 \\
\hline Mean age of network members in years & 24.73 & 6.58 \\
\hline Mean network stabilityc & 4.55 & .64 \\
\hline Mean frequency of network interaction ${ }^{\mathrm{d}}$ & 3.21 & .79 \\
\hline Mean network closeness ${ }^{\mathrm{e}}$ & 3.46 & .51 \\
\hline Mean frequency of network conflict ${ }^{f}$ & 1.60 & .59 \\
\hline Number of types of network support from both membersg & 4.77 & 1.83 \\
\hline
\end{tabular}

Analysis restricted to youth who had valid data on all variables.

a Responses ranged from 0 (7th grade or less) to 7 (some college).

$\mathrm{b}$ Responses ranged from 1 (once) to 6 (21-51 times).

${ }^{\mathrm{c}}$ Responses ranged from 1 (known for a few hours) to 5 (known for a year or more).

${ }^{d}$ Responses ranged from 1 (saw once or twice in the past month) to 4 (saw everyday in the past month).

e Responses ranged from 1 (not close at all) to 4 (very close).

${ }^{\mathrm{f}}$ Responses ranged from 1 (never) to 4 (always).

$\mathrm{g}$ Responses ranged from 0 (no support from either member) to 8 (all types of support from both members).

\subsection{Social network characteristics}

Approximately $12 \%$ of respondents reported that at least one of their social network members was a family member. The average age of the network members was $24.73(\mathrm{SD}=6.58)$ and $40 \%$ of respondents reported having had sex with at least one network member. Approximately $70 \%$ of youth had used alcohol with at least one network member and $62 \%$ had used illicit drugs with at least one network member. Further, almost $14 \%$ of young adults were pressured to use drugs and $9 \%$ were pressured to have sex by a network member. On average, youth reported that they had known their network members from a few months to a year or more $(\bar{X}=4.55 ; \mathrm{SD}=.64)$, saw them approximately three times a week or more in the past month $(\bar{X}$ $=3.21 ; \mathrm{SD}=.79)$, were somewhat or very close $(\bar{X}=3.46 ; \mathrm{SD}=.51)$, and reported fighting or arguing sometimes or less $(\bar{X}=1.60 ; \mathrm{SD}=.59)$. Finally, youth reported having access to approximately 5 units of social support out of a possible $8(\bar{X}=4.77 ; \mathrm{SD}=1.83)$.

\subsection{Multivariate results}

The OLS regression models in Table 2 report the standardized beta coefficients $(\beta)$ for correlates of sexual risk taking. In Model 1 , results indicate that older youth $(\beta=.23 ; p \leq .01)$, those with lower levels of education $(\beta=-.22 ; p \leq .01)$, and those who have experienced more sexual victimization $(\beta=.29 ; p \leq .01)$ engaged in significantly more sexual risk taking activities. These control variables explained $24 \%$ of the variance in the dependent variable. 
Table 2. Multiple regression models for correlates of sexual risk taking $(n=145)$.

\begin{tabular}{|c|c|c|c|c|}
\hline & \multicolumn{2}{|c|}{ Model 1} & \multicolumn{2}{|c|}{ Model 2} \\
\hline & $\beta$ & se & $\beta$ & se \\
\hline \multicolumn{5}{|l|}{ Controls } \\
\hline Female & .01 & .18 & .03 & .17 \\
\hline Age in years & $.23^{* *}$ & .04 & $.25^{* *}$ & .04 \\
\hline Heterosexual & -.08 & .23 & -.09 & .22 \\
\hline Education level & $-.22^{* *}$ & .05 & $-.24^{* *}$ & .04 \\
\hline Employed full time & -.10 & .16 & $-.16^{*}$ & .16 \\
\hline Number of times run away & .03 & .05 & .01 & .05 \\
\hline Sexual abuse & .09 & .04 & .04 & .04 \\
\hline Sexual victimization & $.29^{* *}$ & .07 & $.21^{*}$ & .07 \\
\hline \multicolumn{5}{|l|}{ Network Characteristics } \\
\hline \multicolumn{3}{|c|}{ Mean age of network members in years } & .10 & .01 \\
\hline \multicolumn{3}{|c|}{ Family member in network } & $-.16^{*}$ & .25 \\
\hline \multicolumn{3}{|l|}{ Sex partner in network } & .09 & .19 \\
\hline \multicolumn{3}{|c|}{ Has used alcohol with a network member } & $.14 \dagger$ & .19 \\
\hline \multicolumn{3}{|c|}{ Has used drugs with a network member } & .12 & .17 \\
\hline \multicolumn{3}{|c|}{ Pressured to have sex by network member } & -.03 & .30 \\
\hline \multicolumn{3}{|c|}{ Pressured to use drugs by network member } & -.06 & .25 \\
\hline \multicolumn{3}{|l|}{ Mean network stability } & .02 & .13 \\
\hline \multicolumn{3}{|c|}{ Mean frequency of network interaction } & -.07 & .10 \\
\hline \multicolumn{3}{|l|}{ Mean network closeness } & .05 & .17 \\
\hline \multicolumn{3}{|c|}{ Mean frequency of network conflict } & $.24^{* *}$ & .16 \\
\hline \multicolumn{3}{|c|}{ Number of types of support from both network members } & -.05 & .04 \\
\hline Adjusted $R^{2}$ & & .24 & & .35 \\
\hline
\end{tabular}

Model 2, which added in the social network characteristics, revealed that not having a family member present in the network was significantly associated with participation in a greater number of sexual risk taking activities $(\beta=-.16 ; p \leq .05)$. Youth who had used alcohol with a member of their network $(\beta=.14$; $p \leq .10)$ and those with a greater level of conflict within their network $(\beta=.24 ; p \leq .01)$ engaged in significantly more sexual risk taking. The control variables generally remained unchanged except that young adults who were employed less than full time $(\beta=-.16 ; p \leq .05)$ were more likely to engage in greater numbers of unsafe sexual behaviors. The adjusted $R^{2}$ for this block of variables was .35 , which represented a significant improvement from the previous model (F-change $=2.91 ; p \leq .01)$.

The OLS regression models for correlates of drug related behaviors are presented in Table 3. In Model 1, results indicate that males $(\beta=-.23 ; p \leq .01)$, older youth $(\beta=.14 ; p \leq .10)$, those with lower levels of education $(\beta=-.17 ; p \leq .05)$, those employed full time $(\beta=.21 ; p \leq .01)$, those who have run away more often $(\beta=.14$; $p \leq .10)$, and youth who have experienced more physical abuse $(\beta=.16 ; p \leq .05)$ engaged in significantly more drug related behaviors. These control variables explained $19 \%$ of the variance in the dependent variable.

Model 2, which added the social network characteristics, revealed that not having a family member present $(\beta=-.18 ; p \leq .01)$ was associated with more drug related behaviors. Having older network members $(\beta=.19 ; p \leq .01)$ and having used illicit drugs with a network member $(\beta=.46 ; p \leq .01)$ was correlated with having engaged in more substance use related behaviors. Additionally, having a higher level of conflict within one's network led to more drug related behaviors $(\beta=.17 ; p \leq .05)$. The control variables generally remained unchanged except that number of times run away and physical abuse dropped to non-significance in Model 2. The adjusted $R^{2}$ for this model was .40, which represented a significant improvement over the previous model ( $\mathrm{F}$-change $=4.94 ; p \leq .01$ ). 
Table 3. Multiple regression models for correlates of drug related behaviors $(n=145)$.

\begin{tabular}{|c|c|c|c|c|}
\hline & \multicolumn{2}{|l|}{ Model 1} & \multicolumn{2}{|c|}{ Model 2} \\
\hline & $\beta$ & se & $\beta$ & se \\
\hline \multicolumn{5}{|l|}{ Controls } \\
\hline Female & $-.23^{* *}$ & .25 & $-.23^{* *}$ & .22 \\
\hline Age in years & $.14 \dagger$ & .06 & $.15^{*}$ & .05 \\
\hline Heterosexual & -.05 & .32 & -.03 & .29 \\
\hline Education level & $-.17^{*}$ & .07 & $-.20^{* *}$ & .06 \\
\hline Employed full time & $.21^{* *}$ & .24 & $.14^{*}$ & .22 \\
\hline Number of times run away & $.14 \dagger$ & .08 & .10 & .07 \\
\hline Physical abuse & $.16^{*}$ & .05 & .08 & .04 \\
\hline Caretaker drug problem & .07 & .29 & .00 & .26 \\
\hline \multicolumn{5}{|l|}{ Network Characteristics } \\
\hline \multicolumn{2}{|c|}{ Mean age of network members in years } & $.19^{* *}$ & .02 & \\
\hline \multicolumn{2}{|c|}{ Family member in network } & & $-.18^{* *}$ & .35 \\
\hline \multicolumn{2}{|l|}{ Sex partner in network } & & -.01 & .26 \\
\hline \multicolumn{2}{|c|}{ Has used alcohol with a network member } & & -.02 & .26 \\
\hline \multicolumn{2}{|c|}{ Has used drugs with a network member } & $.46^{* *}$ & .25 & \\
\hline \multicolumn{2}{|c|}{ Pressured to have sex by network member } & & -.10 & .41 \\
\hline \multicolumn{2}{|c|}{ Pressured to use drugs by network member } & & -.03 & .37 \\
\hline \multicolumn{2}{|c|}{ Mean network stability } & & -.03 & .19 \\
\hline \multicolumn{2}{|c|}{ Mean frequency of network interaction } & .02 & .15 & \\
\hline \multicolumn{2}{|l|}{ Mean network closeness } & & .01 & .24 \\
\hline \multicolumn{2}{|c|}{ Mean frequency of network conflict } & & $.17^{*}$ & .22 \\
\hline \multicolumn{2}{|c|}{ Number of types of support from both network members } & -.03 & .06 & \\
\hline Adjusted $R^{2}$ & .19 & & .40 & \\
\hline
\end{tabular}

${ }^{*} p \leq .05 . \quad{ }^{* *} p \leq .01 . \quad \dagger p \leq .10$.

\section{Discussion}

The first goal of this study was to describe the social network characteristics of homeless young adults. Results show that these young people have social networks that are comprised mainly of peers. Only $12 \%$ of the sample report having a family member present which is unfortunate given the buffering effect that family members have on homeless youth's participation in risky behaviors (Ennett et al., 1999a; Johnson et al., 2005; Milburn et al., 2005). The majority of youth reported having used alcohol or drugs with a network member although only a small portion of youth (14\%) experienced pressure to use drugs by these members. Although it cannot be determined if youth began using alcohol or drugs prior to joining a network or whether usage began after they joined a group, it is likely that youth in substance using networks will use substances themselves (Kipke et al., 1998).

The findings also reveal that homeless youths' social networks are marked by stability, frequent interaction, closeness, and perceived available social support. Although some fighting or arguing with network members exists, it does not occur on a regular basis. The univariate statistics for social network characteristics of homeless young adults suggest two things. First, networks are not transient or void of support and contact; homeless youth have frequent and consistent contact with network members and they feel close and perceive support to be available. Second, their network members, the majority of whom are similarly aged peers, engage in risky behaviors and, in some cases, pressure the homeless young adult to partake in these activities. Consistent with prior research on homeless youth, these descriptive findings suggest that social networks can have both positive and negative effects (cf. Rice et al., 2007). The first role is that social networks provide some protective functions such as stability and social support for its group members (Hagan and McCarthy, 1997; Ennett et al., 1999a). The second role that networks play is that of instigator: certain network characteristics are harmful because they are associated with homeless youth's participation in risky sexual or drug related behaviors (Kipke et al., 1996; Whitbeck and Hoyt, 1999; Tyler et al., 2001; McMorris et al., 2002; Rice et al., 2007). If the attitudes, norms, and behaviors of the group are consistent with drug and alcohol use or risky 
sexual behavior, these behaviors will be valued and thus more opportunities to partake in them will exist for young people (Bauman and Ennett, 1996). Overall, the harmful effects of network peers on homeless youths activities is balanced, at least to some extent by the positive functions that network members provide.

The second goal of this study was to examine whether social network characteristics are associated with risky sex and substance use related behaviors beyond that explained by both the young adult's own characteristics and their early family histories. The social network variables in both the sexual risk taking and drug related models explain significant variance beyond that of the control variables and supports the contention that homeless youth's social networks are important correlates of their own risky behaviors. That is, having used alcohol or illicit drugs with a network member is associated with engaging in a greater number of risky behaviors. If friends are using alcohol or drugs, it is likely that the group norms are consistent with such behaviors and the homeless youth has more opportunities for substance use through modeling of other members (Bauman and Ennett, 1996). Research also finds that homeless youth who experience coercion from their peers to use alcohol or drugs often give into the pressure (Tyler and Johnson, 2006a). Therefore, strong group norms about using substances may be evident by the fact that many youth are using alcohol and drugs with their group members. Substance use within the network may increase the number of sexual risk taking activities that youth engage in because it puts youth in vulnerable positions where their capacity to decline sexual advances may be impaired (Tyler et al., 2004).

Higher levels of conflict with network members also leads to greater sexual risk taking and drug related behaviors. Although networks of homeless youth may have more stability and support than previously thought, the culture of homelessness includes a relatively high level of "drama" and conflict, which can have deleterious effects on youth who face numerous daily adversities.

Having a family member in one's social network was significantly associated with less sexual risk taking and lower participation in drug related behaviors, which is consistent with the literature. That is, having a family member in one's network buffers against participation in high-risk behaviors (Johnson et al., 2005; Milburn et al., 2005) and family support can be important for homeless youths' overall well-being. Additionally, research finds that homeless youth with ties to extended family members receive offers of shelter, help, and support if needed (Whitbeck and Hoyt, 1999). Having a family member present in their network may translate to having fewer opportunities to engage in high-risk behaviors and having alternative places to stay may result in spending less time on the street, thus decreasing their exposure to high-risk individuals and others who may exploit them (Tyler et al., 2004).

Finally, youth with older peers in their network are likely to engage in more drug related behaviors. It is possible that older peers have been on the streets longer, have more exposure to drug related activities, and thus pass on their drug related knowledge to group members. Therefore, having older members present increases homeless youth's participation in drug related behaviors.

The following limitations should be kept in mind when interpreting these results. First, because the data are cross-sectional it cannot be determined whether network characteristics lead to homeless young adult's risky behaviors or vice versa; only that the two are associated. Second, given the difficulties associated with randomly sampling homeless populations (Wright et al., 1995), this study is not representative of all homeless young adults. The purpose, however, was to include a heterogeneous sample of young adults, including those identified both within service agencies as well as on the street. Third, youth are reporting on very sensitive topics and it is possible that some of them were unwilling to disclose their participation in some of the activities. Consequently, the results may be underestimates of the actual occurrences of high-risk behaviors. Finally, because the number of social network members that youth could nominate was limited to two people, it is not possible to know how extensive their networks really are and how a larger network may have influenced their involvement in risky behaviors. It is also possible, however, that the characteristics of the most important network members were captured in the current study.

Notwithstanding these concerns, these findings suggest that social network characteristics play an important role in homeless youth's own participation in risky behaviors. Even after controlling for youth's own demographic characteristics and family histories, social network characteristics explain a substantial amount of additional variance. Although current descriptive findings indicate that stability, closeness, and frequent interaction are all positive aspects of these young people's social networks, none of these variables 
reached significance at the multivariate level. The results suggest that there is competing influences within social networks of homeless youth. That is, the positive influences tend to be protective factors whereas the negative influences tend to encourage risk-taking behavior but these influences (i.e., the positive effect of family members in one's network and conflict in the network) are concurrent. This finding is supported by the work of Rice et al. (2007) who found that social networks have both protective properties and negative influences on risky behaviors for homeless youth across time.

Given the paucity of research in this area, future research should continue to explore the role that social networks play in homeless youth's risky behaviors. Qualitative studies that are able to tease out how youth identify their networks, what networks mean to them, and how youth make judgments about engaging in risky behaviors within the context of social networks would be particularly useful. Given the important role that social network characteristics have for current study participants, intervention strategies need to target both homeless young adults and their network members. For example, attitudes, behaviors, and norms within networks that discourage risky behaviors are likely to have positive benefits for all members involved. Additionally, youth may require services that include counseling, job training, and employment opportunities in order to reduce their reliance on risky sexual and drug related behaviors. These services may also work toward permanently removing young people from the streets.

\section{Acknowledgment}

This article is based on research supported by a grant from the National Institute of Mental Health (K01MH064897).

\section{References}

Allen et al., 1994 - David M. Allen, Stan Lehman, Timothy A. Green, Mary Lou Lindegren, Ida Onorato, Willis Forrester, and the Field Services Branch, HIV infection among homeless adults and runaway youth, United States, 1989-1992, AIDS 8 (1994), pp. 1593-1598.

Anderson et al., 1994 - John E. Anderson, Thomas E. Freese, and Julia N. Pennbridge, Sexual risk behavior and condom use among street youth in Hollywood, Family Planning Perspective 26 (1994), pp. 22-25.

Bailey et al., 1998 - Susan L. Bailey, Carol S. Camlin, and Susan T. Ennett, Substance use and risky sexual behavior among homeless and runaway youth, Journal of Adolescent Health 23 (1998), pp. 378-388.

Baron, 1999 - Stephen W. Baron, Street youths and substance use: the role of background, street lifestyle, and economic factors, Youth and Society 31 (1999), pp. 3-26.

Bauman and Ennett, 1996 - Karl E. Bauman and Susan T. Ennett, On the importance of peer influence for adolescent drug use: commonly neglected considerations, Addiction 91 (1996), pp. 185-198.

Beech et al., 2002 - Bettina M. Beech, Leann Myers, and Derrick J. Beech, Hepatitis B and C infections among homeless adolescents, Family and Community Health 25 (2002), pp. 28-36.

Booth et al., 1999 - Robert E. Booth, Yiming Zhang, and Carol F. Kwiatkowski, The challenge of changing drug and sex risk behaviors of runaway and homeless adolescents, Child Abuse E Neglect 23 (1999), pp. 1295-1306.

Cairns et al., 1995 - Robert B. Cairns, Man-Chi Leung, and Beverley D. Cairns, Social networks over time and space in adolescence. In: Lisa J. Crockett and Ann C. Crouter, Editors, Pathways Through Adolescence: Individual Development in Relation to Social Contexts, Lawrence Erlbaum Associates, New Jersey (1995), pp. 35-56.

Chen et al., 2004 - Xiaojin Chen, Kimberly A. Tyler, Les B. Whitbeck, and Dan R. Hoyt, Early sexual abuse, street adversity, and drug use among female homeless and runaway adolescents in the Midwest, The Journal of Drug Issues 34 (2004), pp. $1-21$.

Clatts and Davis, 1999 - Michael C. Clatts and W. Rees Davis, A demographic and behavioral profile of homeless youth in New York city: implications for AIDS outreach and prevention, Medical Anthropology Quarterly 13 (1999), pp. 365-374.

Ennett et al., 1999a - Susan T. Ennett, Susan L. Bailey, and E. Belle Federman, Social network characteristics associated with risky behaviors among homeless and runaway youth, Journal of Health and Social Behavior 40 (1999), pp. 63-78.

Ennett et al., 1999b - Susan T. Ennett, E. Belle Federman, Susan L. Bailey, Christopher L. Ringwalt, and Michael L. Hubbard, HIV-risk behaviors associated with homelessness characteristics in youth, Journal of Adolescent Health 25 (1999), pp. 344-353.

Ennew, 1994 - Judith Ennew, Parentless friends: a cross-cultural examination of networks among street children and street youth. In: F. Nestmann and K. Hurrelmann, Editors, Social Networks and Social Support in Childhood and Adolescence, de Gruyter and Co, Berlin (1994), pp. 409-426. 
Fisher, 1988 - Jeffrey D. Fisher, Possible effects of reference group-based social influence on AIDS-risk behavior and AIDS prevention, American Psychologist 43 (1988), pp. 914-920.

Fors and Rojek, 1991 - Stuart W. Fors and Dean G. Rojek, A comparison of drug involvement between runaways and school youth, Journal of Drug Education 21 (1991), pp. 13-25.

Forst, 1994 - Martin L. Forst, Sexual risk profiles of delinquent and homeless youths, Journal of Community Health 19 (1994), pp. 101-114.

Ginzler et al., 2003 - Joshua A. Ginzler, Bryan N. Cochran, Melanie Domenech-Rodriguez, Ana Mari Cauce, and Leslie B. Whitbeck, Sequential progression of substance use among homeless youth: an empirical investigation of the gateway theory, Substance Use and Misuse 38 (2003), pp. 725-758.

Goodman and Berecochea, 1994 - Elizabeth Goodman and John E. Berecochea, Predictors of HIV testing among runaway and homeless adolescents, Journal of Adolescent Health 15 (1994), pp. 566-572.

Greenblatt and Robertson, 1993 - Milton Greenblatt and Marjorie J. Robertson, Life-styles, adaptive strategies, and sexual behaviors of homeless adolescents, Hospital and Community Psychiatry 44 (1993), pp. 1177-1180.

Greene et al., 1997 - Jody M. Greene, Susan T. Ennett, and Christopher L. Ringwalt, Substance use among runaway and homeless youth in three national samples, American Journal of Public Health 87 (1997), pp. 229-235.

Greene et al., 1999 - Jody M. Greene, Susan T. Ennett, and Christopher L. Ringwalt, Prevalence and correlates of survival sex among runaway and homeless youth, American Journal of Public Health 89 (1999), pp. 1406-1409.

Hagan and McCarthy, 1997 - John Hagan and Bill McCarthy, Mean Streets: Youth Crime and Homelessness, Cambridge University Press, New York (1997).

Halcon and Lifson, 2004 - Linda L. Halcon and Alan R. Lifson, Prevalence and predictors of sexual risks among homeless youth, Journal of Youth and Adolescence 33 (2004), pp. 71-80.

Hodgins et al., 1993 - David C. Hodgins, Eleanor Maticka-Tyndale, Nady El-Guebaly, and Malcom Est, The CAST-6: development of a short-form of the children of alcoholics screening test, Addictive Behaviors 18 (1993), pp. 337-345.

Janus et al., 1987 - Mark-David Janus, Arlene McCormack, Ann W. Burgess, and Carol Hartman, Adolescent Runaways: Causes and Consequences, Lexington Books, Lexington, MA (1987).

Johnson et al., 1996 - Timothy P. Johnson, Jeannie R. Aschkenasy, Mary Ruth Herbers, and Stephen A . Gillenwater, Self-reported risk factors for AIDS among homeless youth, AIDS Education and Prevention 8 (1996), pp. 308-322.

Johnson et al., 2005 - Kurt D. Johnson, Les B. Whitbeck and Dan R. Hoyt, Predictors of social network composition among homeless and runaway adolescents, Journal of Adolescence 28 (2005), pp. 231-248.

Kipke et al., 1996 - Michele D. Kipke, Jennifer B. Unger, Raymond F. Palmer, and Renee Edgington, Drug use, needle sharing, and HIV risk among injection drug-using street youth, Substance Use and Misuse 31 (1996), pp. 1167-1187.

Kipke et al., 1997 - Michele D. Kipke, Jennifer B. Unger, Susan O'Connor, Raymond F. Palmer, and Steven R. LaFrance, Street youth, their peer group affiliation and differences according to residential status, subsistence patterns, and use of services, Adolescence 32 (1997), pp. 655-669.

Kipke et al., 1998 - Michele D. Kipke, Jennifer B. Unger, Raymond F. Palmer, Ellen Iverson, and Susan O'Connor, Association between self-identified peer-group affiliation and HIV risk behaviors among street youth. In: J.B. Greenberg and M.S. Neumann, Editors, What We Have Learned from the AIDS Evaluation of Street Outreach Projects, Centers for Disease Control, Atlanta, GA (1998), pp. 61-82.

Koopman et al., 1994 - Cheryl Koopman, Margaret Rosario, and Mary Jane Rotheram-Borus, Alcohol and drug use and sexual behaviors placing runaways at risk for HIV infection, Addictive Behaviors 19 (1994), pp. 95-103.

Kral et al., 1997 - Alex H. Kral, Beth E. Molnar, Robert E. Booth, and John K. Watters, Prevalence of sexual risk behaviour and substance use among runaway and homeless adolescents in San Francisco, Denver and New York city, International Journal of STD \& AIDS 8 (1997), pp. 109-117.

MacKellar et al., 2000 - Duncan A. MacKellar, Linda A. Valleroy, John P. Hoffmann, Donna Glebatis, Marlene LaLota, William McFarland, Johnny Westerhold, and Robert S. Janssen, Gender differences in sexual behaviors and factors associated with nonuse of condoms among homeless and runaway youths, AIDS Education and Prevention 12 (2000), pp. 477-491.

Marsden, 2006 - Peter V. Marsden, Network methods in social epidemiology. In: J. Michael Oakes and Jay S. Kaufman, Editors, Methods in Social Epidemiology, Jossey-Bass Publications, San Francisco (2006), pp. 267-286.

Martinez et al., 1998 - Tina E. Martinez, Alice Gleghorn, Rani. Marx, Kristen Clements, Matthew Boman, and Mitchell H. Katz, Psychosocial histories, social environment, and HIV risk behaviors of injection and noninjection drug using homeless youths, Journal of Psychoactive Drugs 30 (1998), pp. 1-10.

McMorris et al., 2002 - Barbara J. McMorris, Kimberly A. Tyler, Les B. Whitbeck, and Dan R. Hoyt, Familial and 'on-theStreet' risk factors associated with alcohol use among homeless and runaway adolescents, Journal of Studies on Alcohol 63 (2002), pp. 34-43.

Milburn et al., 2005 - Norweeta G. Milburn, Mary Jane Rotheram-Borus, Philip Batterham, Babette Brumback, Doreen Rosenthanl, and Shelley Mallett, Predictors of close family relationships over one year among homeless young people, Journal of Adolescence 28 (2005), pp. 263-275.

Montgomery et al., 2002 - Susanne B. Montgomery, Justeen Hyde, Christine Johnson De Rosa, Louise A. Rohrbach, Susan Ennett, S. Marie Harvey, Michael Clatts, Ellen Iverson, and Michele D. Kipke, Gender differences in HIV risk behaviors among young injectors and their social network members, American Journal of Drug and Alcohol Abuse 28 (2002), pp. 453-475. 
Moon et al., 2000 - Martha W. Moon, William McFarland, Timothy Kellogg, Michael Baxter, Michell H. Katz, Duncan MacKellar, and Linda A. Valleroy, HIV risk behavior of runaway youth in San Francisco: age of onset and relation to sexual orientation, Youth and Society 32 (2000), pp. 184-201.

Rice et al., 2005 - Eric Rice, Norweeta G. Milburn, Mary Jane Rotheram-Borus, Shelley Mallett, and Rosenthal Doreen, The effects of peer group network properties on drug use among homeless youth, American Behavioral Scientist 48 (2005), pp. 1102-1123.

Rice et al., 2007 - Eric Rice, Norweeta G. Milburn, and Mary Jane Rotheram-Borus, Pro-social and problematic social network influences on HIV/AIDS risk behaviours among newly homeless youth in Los Angeles, AIDS Care 19 (2007), pp. 697-704.

Rotheram-Borus and Koopman, 1991 - Mary Jane Rotheram-Borus and Cheryl Koopman, Sexual risk behaviors, AIDS knowledge, and beliefs about AIDS among runaways, American Journal of Public Health 81 (1991), pp. 208-210.

Rotheram-Borus et al., 1992 - Mary Jane Rotheram-Borus, Heino F. Meyer-Bahlburg, Cheryl Koopman, Margaret Rosario, Theresa M. Exner, Ronald Henderson, Marjory Matthieu, and Rhoda Gruen, Lifetime sexual behaviors among runaway males and females, The Journal of Sex Research 29 (1992), pp. 15-29.

Rotheram-Borus et al., 1996 - Mary Jane Rotheram-Borus, Karen A. Mahler, Cheryl Koopman, and Kris Langabeer, Sexual abuse history and associated multiple risk behavior in adolescent runaways, American Journal of Orthopsychiatry 66 (1996), pp. 390-400.

Silbert and Pines, 1981 - Mimi H. Silbert and Ayala M. Pines, Sexual child abuse as an antecedent to prostitution, Child Abuse $\mathcal{E}$ Neglect 5 (1981), pp. 407-411.

Smart and Ogborne, 1994 - Reginald G. Smart and Alan C. Ogborne, Street youth in substance abuse treatment: characteristics and treatment compliance, Adolescence 29 (1994), pp. 733-745.

Straus et al., 1998 - Murray A. Straus, Sherry L. Hamby, David Finkelhor, David W. Moore, and Desmond Runyan, Identification of child maltreatment with the parent-child conflict tactics scales: development and psycho-metric data for a national sample of American parents, Child Abuse E Neglect 22 (1998), pp. 249-270.

Tyler and Johnson, 2006a - Kimberly A. Tyler and Katherine A. Johnson, Pathways in and out of substance use among homeless emerging adults, Journal of Adolescent Research 21 (2006), pp. 133-157.

Tyler and Johnson, 2006b - Kimberly A. Tyler and Katherine A. Johnson, Trading sex: voluntary or coerced? The experiences of homeless youth, Journal of Sex Research 43 (2006), pp. 208-216.

Tyler et al., 2000a - Kimberly A. Tyler, Dan R. Hoyt, and Les B. Whitbeck, The effects of early sexual abuse on later sexual victimization among female homeless and runaway youth, Journal of Interpersonal Violence 15 (2000), pp. 235-250.

Tyler et al., 2000b - Kimberly A. Tyler, Les B. Whitbeck, Dan R. Hoyt, and Kevin A. Yoder, Predictors of self-reported sexually transmitted diseases among homeless and runaway adolescents, The Journal of Sex Research 37 (2000), pp. 369-377.

Tyler et al., 2001 - Kimberly A. Tyler, Dan R. Hoyt, Les B. Whitbeck, and Ana Mari Cauce, The impact of childhood sexual abuse on later sexual victimization among runaway youth, Journal of Research on Adolescence 11 (2001), pp. 151-176.

Tyler et al., 2004 - Kimberly A. Tyler, Les B. Whitbeck, Dan R. Hoyt, and Ana Mari Cauce, Risk factors for sexual victimization among male and female homeless and runaway youth, Journal of Interpersonal Violence 19 (2004), pp. 505-520.

Van Leeuwen et al., 2004 - James M. Van Leeuwen, Christian Hopfer, Sabrina Hooks, Roxane White, Jerene Petersen, and John. Pirkopf, A snapshot of substance abuse among homeless and runaway youth in Denver, Colorado, Journal of Community Health 29 (2004), pp. 217-229.

Wagner et al., 2001 - Lisa Smith Wagner, Linda Carlin, Ana Mari Cauce, and Adam Tenner, A snapshot of homeless youth in Seattle: their characteristics, behaviors and beliefs about HIV protective strategies, Journal of Community Health 26 (2001), pp. 219-232.

Warheit and Biafora, 1991 - George J. Warheit and Frank Biafora, Mental health and substance abuse patterns among a sample of homeless post-adolescents, International Journal of Adolescence and Youth 3 (1991), pp. 9-27.

Wenzel et al., 2006 - Suzanne L. Wenzel, Katrin Hambarsoomian, Elizabeth J. D'Amico, Marcia Ellison, and Joan S. Tucker, Victimization and health among indigent young women in the transition to adulthood: a portrait of need, Journal of Adolescent Health 38 (2006), pp. 536-543.

Whitbeck and Hoyt, 1999 - Les B. Whitbeck and Dan R. Hoyt, Nowhere to Grow: Homeless and Runaway Adolescents and their Families, Aldine de Gruyter, New York, NY (1999).

Whitbeck and Simons, 1990 - Les B. Whitbeck and Ronald L. Simons, Life on the streets: the victimization of runaway and homeless adolescents, Youth E Society 22 (1990), pp. 108-125.

Whitbeck et al., 1999 - Les B. Whitbeck, Dan R. Hoyt, and Kevin A. Yoder, A risk-amplification model of victimization and depressive symptoms among runaway and homeless adolescents, American Journal of Community Psychology 27 (1999), pp. 273-296.

Whitbeck et al., 2001 - Les B. Whitbeck, Dan R. Hoyt, Kevin A. Yoder, Ana Mari Cauce, and Matt Paradise, Deviant behavior and victimization among homeless and runway adolescents, Journal of Interpersonal Violence 16 (2001), pp. 1175-1204.

Wright, 1991 - James D. Wright, Health and the homeless teenager: evidence from the national health care for the homeless program, Journal of Health and Social Policy 2 (1991), pp. 15-36.

Wright et al., 1995 - James D. Wright, Tupper L. Allen, and Joel A. Devine, Tracking non-traditional populations in longitudinal studies, Evaluation and Program Planning 18 (1995), pp. 267-277. 